\title{
Local Cellular Responses to Titanium Dioxide from Orthopedic Implants
}

Jie J. Yao, ${ }^{1, \dagger}$ Eric A. Lewallen, ${ }^{1, \dagger}+$ W William H. Trousdale, ${ }^{1}$ Wei Xu, ${ }^{1,2}$ Roman Thaler, ${ }^{1}$ Christopher G. Salib, Nicolas Reina, ${ }^{1}$ Matthew P. Abdel, ${ }^{1}$ David G. Lewallen, ${ }^{1, *}$ and Andre J. van Wijnen, ${ }^{1, *}$

\begin{abstract}
We evaluated recently published articles relevant to the biological effects of titanium dioxide $\left(\mathrm{TiO}_{2}\right)$ particles on local endogenous cells required for normal bone homeostasis, repair, and implant osseointegration. Structural characteristics, size, stability, and agglomeration of $\mathrm{TiO}_{2}$ particles alter the viability and behavior of multiple bone-related cell types. Resulting shifts in bone homeostasis may increase bone resorption and lead to clinical incidents of osteolysis, implant loosening, and joint pain. $\mathrm{TiO}_{2}$ particles that enter cells (through endocytosis or Trojan horse mechanism) may further disrupt implant retention. We propose that cellular responses to titanium-based nanoparticles contribute to pathological mechanisms underlying the aseptic loosening of titanium-based metal implants.
\end{abstract}

Keywords: adverse local tissue reaction; joint replacement; nanoparticle; total hip arthroplasty; total knee arthroplasty

\section{Introduction}

Total joint arthroplasty (TJA) is the definitive treatment for severely damaged synovial joints (e.g., symptomatic osteoarthritis $\left.{ }^{1,2}\right)$. As the number of TJA patients in the United States rises from an estimated 7 million, ${ }^{3,4}$ demands for revision TJA will concurrently increase. Indications for revision TJA include septic and aseptic etiologies (e.g., dislocations, polyethylene wear, wear-induced osteolysis, implant loosening, and adverse local tissue reactions ${ }^{5,6}$ ), whereas the causes of such complications often go undetected (e.g., latent periprosthetic joint infections), and mechanisms remain unidentified. ${ }^{7}$ Poor surgical technique and implant design cause implant failure, yet $10-15 \%$ of patients experience aseptic implant failure despite well-designed implants and meticulous surgical technique. ${ }^{8-10}$ We propose that the release of titanium nanoparticles may contribute to aseptic implant loosening by negatively influencing periprosthetic skeletal repair cells.
Implant materials can corrode, degrade, and wear (i.e., tribocorrosion), adding particles to the intraarticular joint space that may impede healing of boneimplant interfaces. ${ }^{11-13}$ Metal implants are naturally protected from extensive corrosion by a surface oxide layer, but mechanical stress can overwhelm the protective capacity of this layer and result in the release of harmful metallic particles. ${ }^{14}$ Particles that enter the joint space, periprosthetic bone, surrounding soft tissues, and distal tissues ${ }^{15-17}$ cause aseptic implant loosening, ${ }^{18}$ adverse local tissue reactions, ${ }^{19}$ and/or systemic toxicity, ${ }^{20}$ all of which can lead to significant patient discomfort and inconvenience. Nonmetal and metal particles likely have a synergistic effect toward implant loosening; however, concentration-dependent patterns of localized tissue/joint damage caused by debris release have not been clearly established and may vary greatly by patient.

The adverse effects of metallic orthopedic particles are of great increased interest, in part, because of the

\footnotetext{
${ }^{1}$ Department of Orthopedic Surgery, Mayo Clinic, Rochester, Minnesota.

${ }^{2}$ Department of Orthopedics, Second Affiliated Hospital of Soochow University, Suzhou, China.

These authors contributed equally.

Current address: Department of Biological Sciences, Hampton University, Hampton, Virginia.
}

*Address correspondence to: David G. Lewallen, MD, Department of Orthopedic Surgery, Mayo Clinic, 200 First Street SW, Rochester, MN 55905, E-mail: lewallen .david@mayo.edu or Andre J. van Wijnen, PhD, Department of Orthopedic Surgery, Mayo Clinic, 200 First Street SW, Rochester, MN 55905, E-mail: vanwijnen .andre@mayo.edu

(C) Jie J. Yao et al. 2017; Published by Mary Ann Liebert, Inc. This is an Open Access article distributed under the terms of the Creative Commons Attribution License, which permits unrestricted use, distribution, and reproduction in any medium, provided the original work is properly cited. 
large-scale recalls of metal-on-metal implants that have had significant economic costs to the healthcare industry. $^{21-23}$ For example, cobalt and chromium particles disrupt cells locally and have been implicated in systemic disorders such as hypothyroidism, cardiomyopathy, or neuroocular disease. ${ }^{19,20,24,25}$ Although titanium alloys are thought to be biologically inert, ${ }^{26}$ they may be a source of titanium dioxide $\left(\mathrm{TiO}_{2}\right)$ particles that influence human cells. The potential effects of $\mathrm{TiO}_{2}$ particles need to be further investigated, particularly in the microenvironment of mesenchymal skeletal repair cells within synovial joints, where the largest titanium implants are typically applied. ${ }^{27}$ Specifically, the biological, physical, and chemical interactions between $\mathrm{TiO}_{2}$ nanoparticles and endogenous bone-forming cells (e.g., osteoblasts, osteocytes) need to be characterized to better formulate strategies that reduce nanoparticlebased implant loosening. This review examines recent findings on the cellular effects of $\mathrm{TiO}_{2}$ nanoparticles in the peri-implant joint microenvironment. Specifically, particle size, aggregation, structure, uptake, and endocytosis, as well as the intra- and extracellular effects of titanium particle exposure, are discussed within the context of cell viability, behavior, and phenotypic change. ${ }^{28,29}$ Findings that facilitate a focus on clinically relevant information that could be eventually translated into novel prophylactic and therapeutic options for minimizing aseptic orthopedic implant loosening are highlighted.

\section{Characteristics of Tribocorrosion-Produced Titanium Particles}

Orthopedic implants form a passivating superficial $\mathrm{TiO}_{2}$ film that can prevent extensive corrosion. ${ }^{14}$ However, implant wear degrades this $\mathrm{TiO}_{2}$ layer, resulting in depassivation, bare metal exposure, repassivation, and corrosion ${ }^{30,31}$ (Fig. 1). In vivo corrosion and wear of titanium implants can, therefore, produce a diverse group of $\mathrm{TiO}_{2}$, inorganic metallic salts, as well as free metal ions. ${ }^{32}$ Tribocorrosion-produced $\mathrm{TiO}_{2}$ particles are mineral oxides that exist in different phases, most commonly rutile and anatase, ${ }^{33-35}$ which can be harmful to some cell types. Similar to concentration and exposure time, critical relationships between size, phase, and stability likely influence the cytotoxicity of particles $^{36-38}$ (Table 1).

Particle sizes need to be considered independently regarding their potential effects on aseptic implant loosening. ${ }^{15,34,39,40}$ In addition, $\mathrm{TiO}_{2}$ nanoparticles aggregate in the extracellular space or perinuclear cyto- sol, ${ }^{29,41,42}$ causing agglomerations that may be part of the cytoprotective response of cells to the presence of nanoparticles. Most biological characterizations of nanomaterial-cell interactions have focused on particles smaller than $100 \mathrm{~nm}$ and demonstrated surface area-related effects that increase as particle sizes decrease. $^{39}$ At smaller particle diameters, the surface area-to-volume ratio increases and surface properties exert a more dominant influence on bioreactivity. ${ }^{34,40}$ Therefore, ultrafine particles may exhibit different properties than larger, coarse particles ${ }^{34}$ or particle agglomerations, which emphasizes the importance of accurately characterizing particle size distributions in clinical samples used for diagnosing aseptic implant loosening. Particle size not only affects nanoparticle-cell interactions but also influences the transportability of particles within a joint and throughout the body.

Although a combination of differently sized particles may be present in vivo, their distribution is heterogeneous. For example, Maloney et al. ${ }^{15}$ found that $>90 \%$ of particles were $<1000 \mathrm{~nm}$ in digested peri-implant tissues. Examination of lymphatic, splenic, and hepatic tissues from TJA patients has also shown that most disseminated particles were $<1000 \mathrm{~nm}$ in size. ${ }^{17}$ Smaller particles enter cells more easily by phagocytosis and should be considered more bioreactive. ${ }^{43,44}$ Furthermore, the ability of nanoparticles to aggregate may increase their observed size. ${ }^{29,42,45-47}$ Agglomerates are often found in vitro, but they may be quite unstable and dissociate into their constituent nanoparticles in vivo. ${ }^{34}$ Equally important to aseptic loosening is the recirculation of dissociated particles within synovial joints, causing catalytic cytotoxic effects and/or adverse local tissue reactions (e.g., pseudotumor formation). The cell cycle responses to the presence of nanoparticles (e.g., endocytosis, apoptosis) will provide relevant opportunities for therapeutic intervention strategies that minimize their negative effects.

\section{Cellular Uptake and Cytotoxicity of $\mathrm{TiO}_{2}$ Nanoparticles}

The primary mechanism of $\mathrm{TiO}_{2}$ nanoparticle cellular uptake is thought to be endocytosis. ${ }^{29,48-50}$ Using pharmacological inhibitors of endocytosis, Cai et al. ${ }^{29}$ demonstrated a relationship between particle size and mode of endocytosis. Specifically, small $(14 \mathrm{~nm})$ particles were taken in by caveolae, whereas larger (74 and $196 \mathrm{~nm})$ particles were taken in by clathrin-coated pits. ${ }^{29}$ To further confirm the role of endocytosis, an adenosine triphosphate (ATP)-dependent process, these authors inhibited ATP production through application 

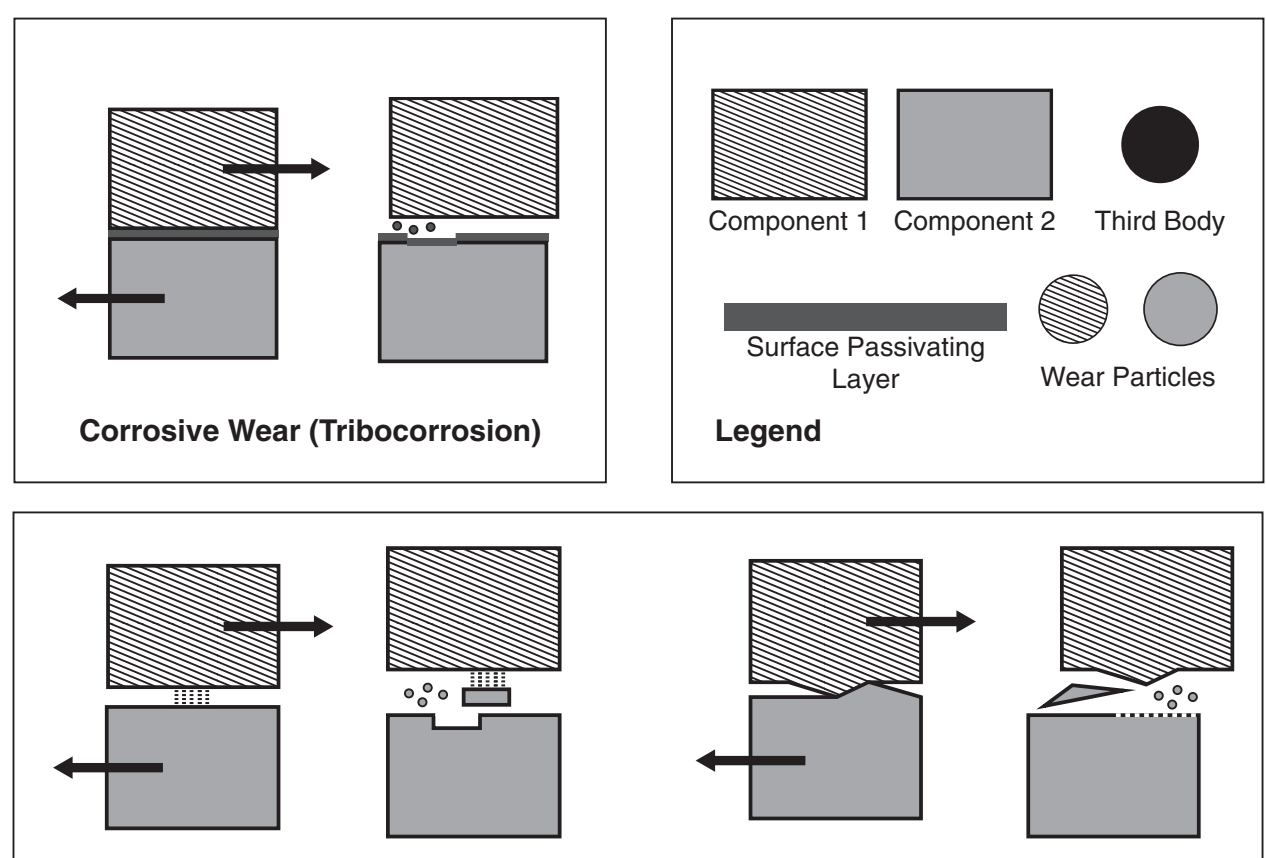

Adhesive Wear

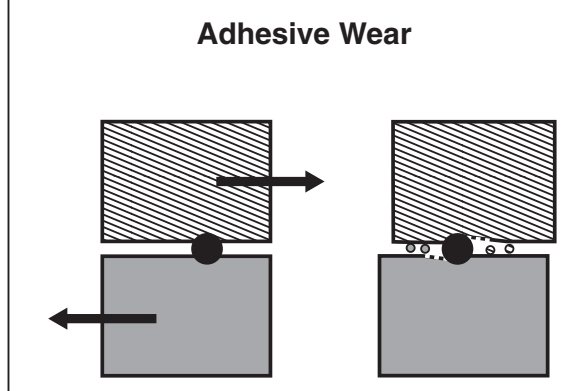

Third- Body Wear

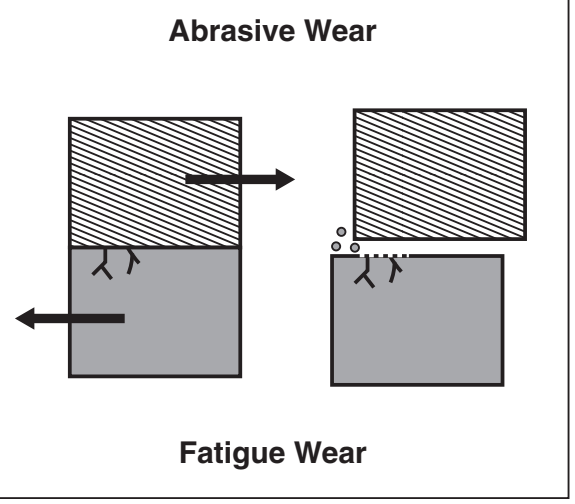

FIG. 1. Types of wear/corrosion that contribute to $\mathrm{TiO}_{2}$ nanoparticle release after orthopedic implant placement. Corrosive wear: a corrosive layer forms on the surface of metal implants. Adhesive wear: atomic forces between two surfaces can exceed the strength of one or both surface(s). Relative movement of the two surfaces generates particles of multiple sizes. Abrasive wear: with two materials of different hardness, the softer material will generate particles through mechanical stress exerted by the harder surface. Third-body wear: a third body becomes embedded between two articulating surfaces and additional particles are generated along the path of third body movement. Fatigue: shear stress and/or strain can exceed the fatigue limit of a material, releasing particles.

of $\mathrm{NaN}_{3}$ in combination with reduced temperature $\left(4^{\circ} \mathrm{C}\right)$ and found a significant decrease in the uptake of $14 \mathrm{~nm}$ particles (to $16.73 \%$ at $4^{\circ} \mathrm{C} ; 26.28 \%$ when exposed to $\left.\mathrm{NaN}_{3}\right){ }^{29}$ However, alternative pathways to endocytosis and the entry of nanoparticles into cells still need to be considered, as many other forms of cellular membrane transport are energy dependent and potentially useful for reducing any harmful effects of nanoparticles.
In addition to $\mathrm{TiO}_{2}$ nanoparticles observed within endosomes, unbound nanoparticles have been discovered in the cytosol, ${ }^{48,51}$ likely from degraded endosomes. Alternatively, nanoparticles may be transported through membrane pores, specific transporters, or a Trojan horse effect $^{48,49,52}$ (Fig. 2). Regarding a possible Trojan horse effect, $\mathrm{TiO}_{2}$ nanoparticles form a core of biocomplexes rich in calcium and phosphorus that in principle remain 


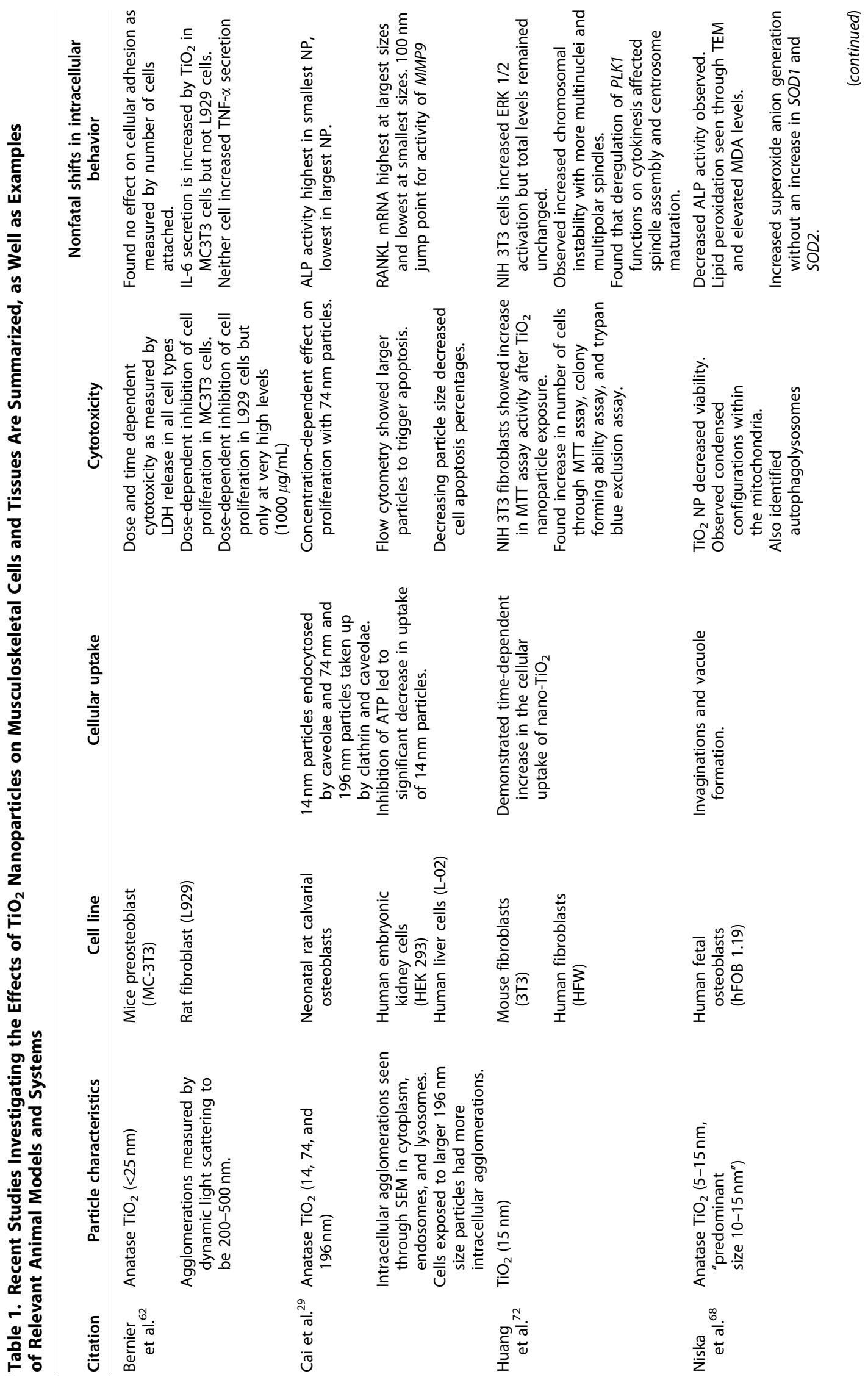




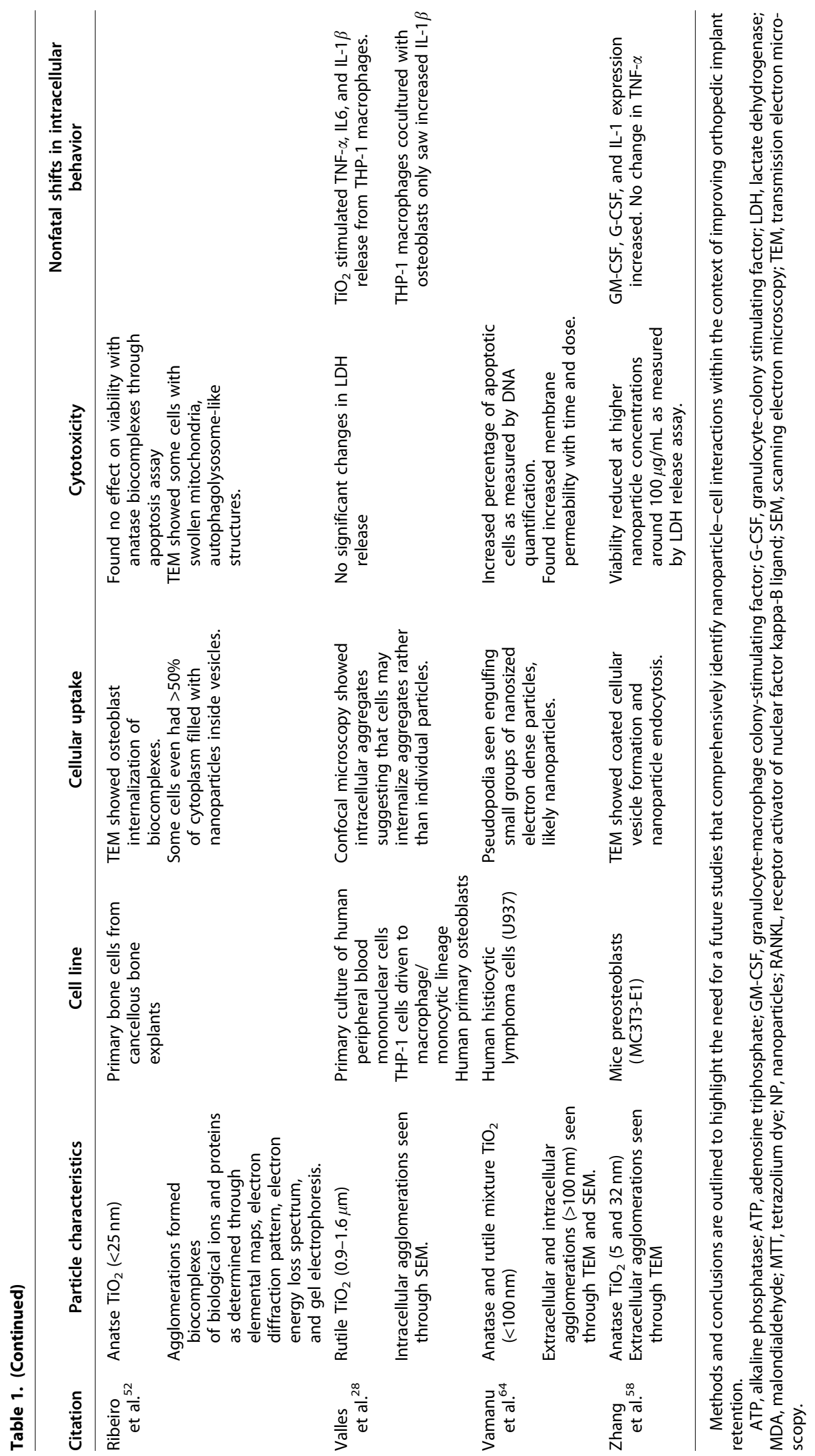



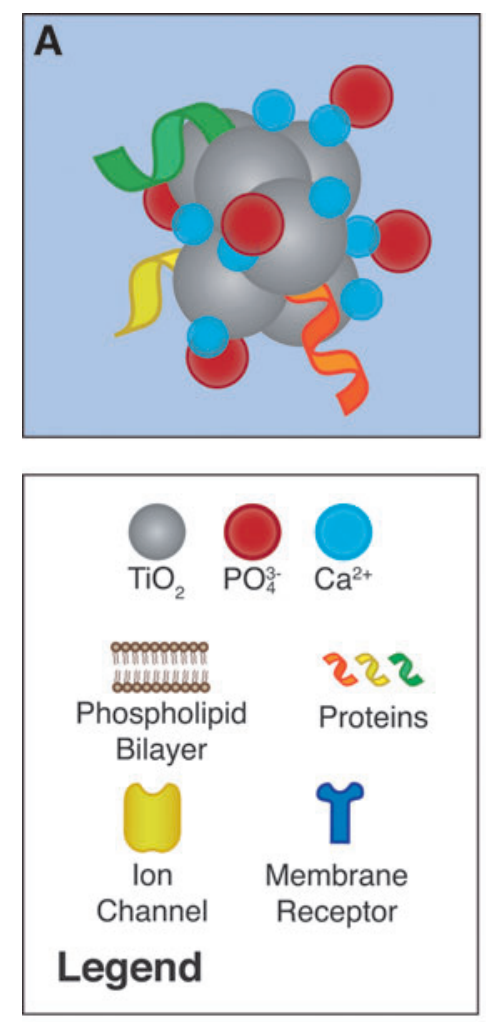

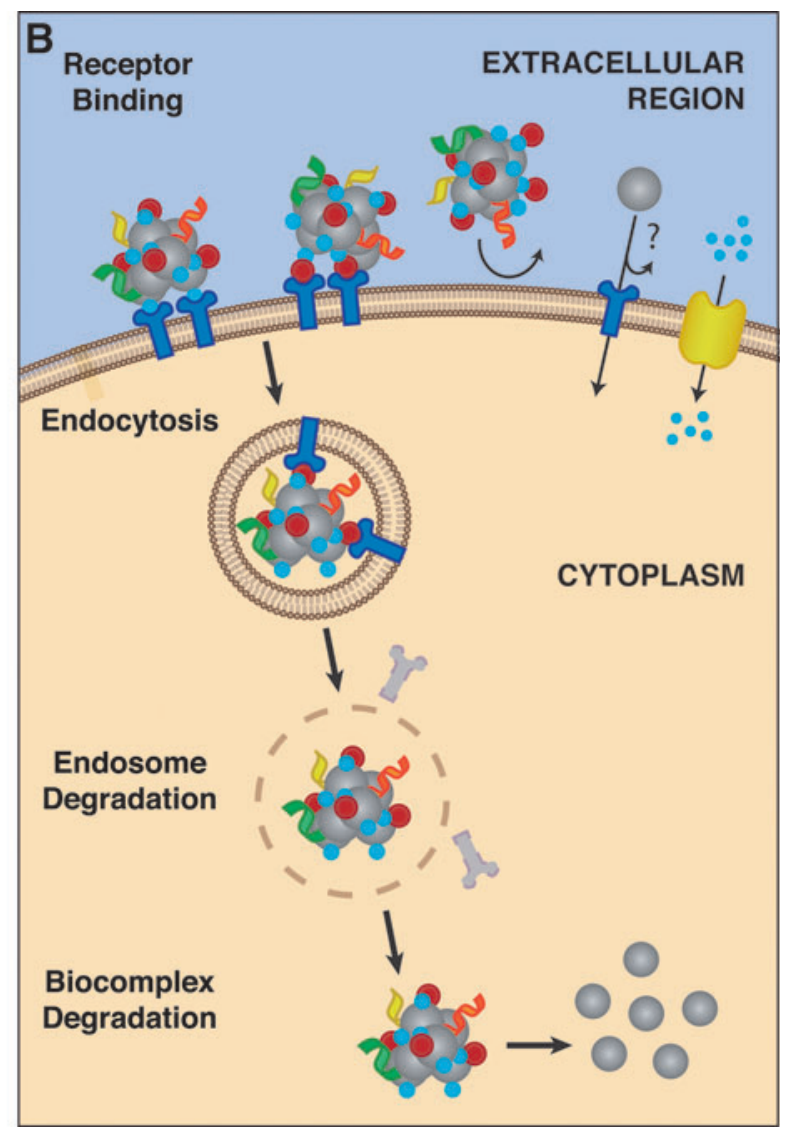

FIG. 2. A Trojan horse mechanism as a proposed mechanism for the internalization of $\mathrm{TiO}_{2}$ nanoparticles. (A) $\mathrm{TiO}_{2}$ nanoparticles can form biocomplexes consisting of a $\mathrm{TiO}_{2}$ core surrounded by ions such as calcium and phosphorus that associate with proteins. (B) The surrounding shell of calcium, phosphorus, and protein hides $\mathrm{TiO}_{2}$ nanoparticles from cell surface receptors. Once internalized, biocomplexes dissociate and $\mathrm{TiO}_{2}$ nanoparticles can spread throughout the cytosol to effect cellular functions and homeostasis. This Trojan horse mechanism may also be involved in clathrin- and caveolae-mediated endocytosis of $\mathrm{TiO}_{2}$, although it remains unclear whether $\mathrm{TiO}_{2}$ nanoparticles can enter cells without a Trojan horse (or similar) mechanism (indicated by ? in figure).

undetected by cells. Association of biocomplexes with glycoproteins such as fetuin A (alpha-2-HS-glycoprotein [AHSG]) would further facilitate endocytosis. As biocomplexes dissociate within cells, the $\mathrm{TiO}_{2}$ nanoparticles are released into the cytosol where they may provoke cytotoxic responses. ${ }^{52}$ Although membrane ATPases and transporters (e.g., natural resistance-associated macrophage proteins) have been characterized for other metal ions, ${ }^{53,54}$ titanium-specific transporters are not known. Upon entry into cells, $\mathrm{TiO}_{2}$ nanoparticles have size-dependent mechanisms (extracellular and intracellular processes) that influence cell growth, protein production, and cellular phenotypes that may initiate (or accelerate) aseptic loosening.
A size-toxicity relationship has been described for some nanoparticles (e.g., $\mathrm{CuO}, \mathrm{Ag}$ ) and cells, such that smaller nanoparticles are more harmful, yet for $\mathrm{TiO}_{2}$ the evidence remains inconclusive. A study of rat neonatal calvarial osteoblasts compared the effects of anatase phase $\mathrm{TiO}_{2}$ of various sizes (ranging from 14 to $196 \mathrm{~nm}$ ) and found no significant differences in cellular morphology among treatments. ${ }^{29}$ Larger particles and aggregations may remain in the cytosol and interfere with cellular processes. ${ }^{29,55}$ A later investigation of rat mesenchymal stem/stromal cells (MSCs) compared 14, 108, and $196 \mathrm{~nm}$ diameter particles and found that cell viability, proliferation, cell cycle progression, cell adhesion, and cell migration decreased with 
increasing nanoparticle size. ${ }^{42}$ Consistent with work on other cell lines, ${ }^{56,57}$ osteogenic differentiation was reduced in cells exposed to larger nanoparticles, ${ }^{42}$ suggesting that particle size and agglomeration chemistry may influence cell biology and/or aseptic loosening processes. In addition to modulating cell behavior, $\mathrm{TiO}_{2}$ nanoparticles can directly affect cell viability. Increases in regulated cell death among osteoblast lineage cells have been observed after exposure to nano- and microparticles. ${ }^{45,50,51,58-61}$ Mitochondrial and cell membrane permeability both increase in the presence of $\mathrm{TiO}_{2}$ particles, suggesting significant cell stress. ${ }^{58,62}$ Investigations involving human MSCs, osteoclasts, and histiocytic lymphoma cells have confirmed similar responses, ${ }^{41,60,63,64}$ yet the current challenge is to define how these cells interact with other peri-implant cell types such as preosteoblasts and osteoblasts.

$\mathrm{TiO}_{2}$ nanoparticles likely induce apoptosis through both direct and indirect mechanisms. ${ }^{65,66}$ The induction of apoptosis across a number of cell types suggests a universal mechanism of dose-related DNA damage and oxidative stress. ${ }^{41,63,64,67,68} \mathrm{TiO}_{2}$ nanoparticles may also react with membrane components, leading to reactive oxygen species, leakage of $\mathrm{Ca}^{2+}, \mathrm{Ca}^{2+}$-dependent endonuclease activation, and apoptosis. ${ }^{63}$ Documented high concentrations of $\mathrm{TiO}_{2}$ nanoparticles that cause direct genotoxicity and apoptosis ${ }^{20,37,63,69-73}$ provide a logical starting point for in vitro experiments, which should reveal the dose-dependent mechanisms responsible for $\mathrm{TiO}_{2}$-related processes of aseptic orthopedic implant loosening. $\mathrm{TiO}_{2}$ nanoparticle localization within the nucleus has not been widely documented, but particle aggregates have been observed in the perinuclear region. $^{20,29,37,41,42,46,62,63,69-74}$ This indicates an indirect mechanism of genotoxicity related to cellular stress. However, localization of $\mathrm{TiO}_{2}$ has only been reported in one study of periodontal ligament cells, ${ }^{75}$ whereby particles may have transported through nuclear pores or fused vesicles into the nucleus, a phenomenon previously described for Ag nanoparticles. ${ }^{75,76}$ Cell-specific observations of nanoparticle accumulation within the nucleus and organelles will help identify which cells are most vulnerable to $\mathrm{TiO}_{2}$ exposure and the possible mechanisms of nanoparticle incursion into joints after TJA.

Interpretation of reported nanoparticle sizes can be particularly difficult given the irrepressible tendency of these nanoparticles to agglomerate. Of note is the possibility that interstitial void spaces among loosely aggregated nanoparticles may provide adequate substrates for the attachment and functionalization of or- ganic molecules (Fig. 2). Nonetheless, reported individual particle sizes may be misleading if aggregations are frequently formed. As bioreactivity is widely believed to be related to surface area, aggregations of nanoparticles may, therefore, exhibit different toxicity and abilities to enter cells than their constituent particles. The potential for nanoparticle aggregations to dissolve in vivo complicates the correlation between in vivo and in vitro data. Studies that incorporate both approaches in conjunction with clinical samples and data will yield useful information to guide clinical approaches that reduce aseptic implant loosening rates.

\section{Indirect Effects of $\mathrm{TiO}_{2}$ Exposure on Cell Viability}

Indirect effects of titanium particle exposure on cell viability have also been proposed. For example, extraction of conditioned media from human MSCs exposed to submicron titanium was cytotoxic to naive human MSCs and induced apoptosis in the absence of particles. However, dilution of the conditioned media to a 1:1 ratio abolished this effect, suggesting a critical concentration of signaling factors. ${ }^{60} \mathrm{TiO}_{2}$ particle-induced apoptosis also exhibits both dose and time dependency. Although the translation of these findings to in vivo systems is less obvious, the identification of thresholds indicates dysregulation of cellular regulatory mechanisms after a critical concentration is surpassed. ${ }^{60}$

Importantly, cellular apoptosis in reaction to $\mathrm{TiO}_{2}$ nanoparticles is the result of both direct and indirect processes. $\mathrm{TiO}_{2}$ first causes oxidative stress and direct injury to cells, and subsequently accelerates the inflammatory cascade by paracrine cytokine release, which is followed by increased apoptosis. However, $\mathrm{TiO}_{2}$ particles do not always induce oxidative stress and cell death in stress-tolerant cells (e.g., endothelial cells) ${ }^{77,78}$ Yet in the presence of significant cellular stress, tissue necrosis can contribute to cell death. For example, histiocytic lymphoma cells (U937) show morphological characteristics consistent with both apoptosis and necrosis. ${ }^{64}$

Other researchers have suggested that rutilestructured $\mathrm{TiO}_{2}$ particles induce apoptosis, whereas anatase-structured $\mathrm{TiO}_{2}$ particles may increase necrosis. ${ }^{79}$ Importantly, experimental knockouts of key apoptosis molecules (e.g., Bak and Bax) exhibit significant cell death in the presence of $\mathrm{TiO}_{2}$, clearly highlighting the important contribution of necrosis. ${ }^{80-82}$ Apoptosis (programmed cell death) and necrosis (nonspecific cell death) together provide complementary mechanisms to detrimentally impact peri-implant 
tissues and cells, and may compound complications of aseptic orthopedic implant loosening.

\section{Bone-Related Effects of $\mathrm{TiO}_{2}$ Exposure}

Consistent with patterns of osteolysis and/or periprosthetic fractures observed in patients with aseptic loosening, $\mathrm{TiO}_{2}$ particles are known to increase bone resorption. ${ }^{83-85}$ Specific consequences of $\mathrm{TiO}_{2}$ nanoparticle exposure to osteoblasts include increased cell death, mitochondrial membrane permeability, lactate dehydrogenase release, and gene expression alterations (e.g., TNFSF11). ${ }^{29,58,62}$ Preosteoblasts (MC3T3E1) may be particularly sensitive to $\mathrm{TiO}_{2}$ nanoparticles, as they exhibit decreased proliferation even at extremely low concentrations $(20 \mu \mathrm{g} / \mathrm{mL}){ }^{58,62}$ In contrast, fibroblastic (L929) cells maintain normal cell proliferation rates until exposure to higher concentrations of $\mathrm{TiO}_{2}$ $(>500 \mu \mathrm{g} / \mathrm{mL}) .{ }^{62}$ Heterogeneity in the responses of different cell types to elevated $\mathrm{TiO}_{2}$ concentrations make the assessment of in vivo consequences challenging, particularly when multiple cell types interact to form healthy bone tissue and a well-fixed orthopedic implant.

Osteogenic differentiation of human MSCs into osteoblasts is suppressed by exposure to submicron Ti particles. ${ }^{60,61}$ In addition, human MSCs exposed to $\mathrm{TiO}_{2}$ exhibit structural alterations (e.g., deregulated actin skeleton formation, decreased integrin-binding sialoprotein expression, diminished collagen Type I (COL1A1), and integrin-binding bone sialoprotein (IBSP) production, inhibited ECM formation), decreased cellular viability, and slower cellular proliferation. ${ }^{45,60,61} \mathrm{TiO}_{2}$ may be both cytotoxic to osteoblast precursors and inhibit the formation of new osteoblasts, thus preventing new bone formation and hindering implant fixation. Nonetheless, the identification and timing of events that lead to aseptic implant loosening need to be better contextualized within a framework of measured $\mathrm{TiO}_{2}$ particle release in vivo.

$\mathrm{TiO}_{2}$ particle exposure may also increase the secretion of matrix proteases by osteoblasts. For example, coarse $\mathrm{TiO}_{2}$ particles ( $4.5 \mu \mathrm{m}$ mean size) increased the expression of genes related to metallopeptidase activity (e.g., Mmp2 and Mt10) in preosteoblasts (MC3T3-E1), but did not alter Timp2 expression. ${ }^{86}$ Metallopeptidase inhibitors such as TIMP act as negative feedback regulators on the activity of metalloproteases ${ }^{87}$ and increase bone resorption. Further compounding bone resorption, the proteolytic activity of MMP2 protein may be increased in the presence of $\mathrm{TiO}_{2}$ particles. ${ }^{83}$ In summary, larger particles alter extracellular processes, smaller particles enter cells to disrupt intracellular processes, and the viability of endogenous skeletal repair cells can be modulated by direct and indirect mechanisms of $\mathrm{TiO}_{2}$ exposure.

\section{Conclusions}

Investigations on the effects of tribocorrosion-produced $\mathrm{TiO}_{2}$ particulate debris on musculoskeletal tissues and cells remain critical given the absolute number of titanium-based surgical implants used in TJA procedures every year. $\mathrm{TiO}_{2}$ nanoparticles have been demonstrated to alter cell viability, behavior, as well as extracellular and intracellular processes. Resulting shifts in bone homeostasis may increase bone resorption and explain clinical findings of osteolysis, loosening, and pain. Future investigations are necessary to identify effects on cells (intra- and extracellular) and better characterize $\mathrm{TiO}_{2}$ nanoparticle behavior in vivo. This remains especially challenging because of technical limitations that preclude accurate measurements of $\mathrm{TiO}_{2}$ nanoparticles in human tissues and cells. However, the findings presented in this review suggest that $\mathrm{TiO}_{2}$ may be an important contributor to aseptic orthopedic implant loosening. Further characterization of inflammatory processes and adverse cellular behaviors upon exposure to multiple sizes of $\mathrm{TiO}_{2}$ particles should yield targets for clinical interpretation and guide novel intervention strategies.

\section{Acknowledgments}

This work was supported by the National Institute of Arthritis and Musculoskeletal and Skin Diseases of the National Institutes of Health under award numbers R01 AR049069 (to A.J.v.W) and F32 AR068154 (to E.A.L.). The content is solely the responsibility of the authors and does not necessarily represent the official views of the National Institutes of Health. We also thank the Mayo Clinic Center for Regenerative Medicine Training and Career Development Award (to R.T.), and the generous philanthropic support from the William H. and Karen J. Eby Foundation.

\section{Author Disclosure Statement}

D.G.L. reports personal fees and other from Stryker, Pipeline Biomedical, Zimmer, and Ketai Medical Devices, as well as patents on selected hip and knee implants with royalties paid by Zimmer. D.G.L. is also employed part time as the Medical Director for The American Joint Replacement Registry. M.P.A. has stock options with Imagen Technologies. No other authors have conflict of interest disclosures. 


\section{References}

1. Krummenauer $F$, Wolf $C$, Gunther KP, et al. Clinical benefit and cost effectiveness of total knee arthroplasty in the older patient. Eur J Med Res. 2009;14:76-84.

2. Jones CA, Beaupre LA, Johnston DWC, et al. Total joint arthroplasties: current concepts of patient outcomes after surgery. Rheum Dis Clin N Am. 2007;33:71-86.

3. Maradit Kremers H, Larson DR, Crowson CS, et al. Prevalence of total hip and knee replacement in the United States. J Bone Joint Surg Am. 2015;97:1386-1397.

4. Kurtz SM, Lau E, Ong K, et al. Future young patient demand for primary and revision joint replacement: national projections from 2010 to 2030. Clin Orthop Relat Res. 2009;467:2606-2612.

5. Bozic KJ, Kurtz SM, Lau E, et al. The epidemiology of revision total knee arthroplasty in the United States. Clin Orthop Relat Res. 2010;468: 45-51.

6. Bozic KJ, Kurtz SM, Lau E, et al. The epidemiology of revision total hip arthroplasty in the United States. J Bone Joint Surg Am. 2009;91: 128-133.

7. Getzlaf MA, Lewallen EA, Kremers HM, et al. Multi-disciplinary antimicrobial strategies for improving orthopaedic implants to prevent prosthetic joint infections in hip and knee. J Orthop Res. 2016;34:177-186.

8. Herberts $\mathrm{P}$, Malchau $\mathrm{H}$. Long-term registration has improved the quality of hip replacement: a review of the Swedish THR Register comparing 160,000 cases. Acta Orthop Scand. 2000;71:111-121.

9. Soderman $\mathrm{P}$, Malchau $\mathrm{H}$, Herberts $\mathrm{P}$. Outcome after total hip arthroplasty: Part I. General health evaluation in relation to definition of failure in the Swedish National Total Hip Arthoplasty register. Acta Orthop Scand. 2000;71:354-359.

10. Labek G, Thaler M, Janda W, et al. Revision rates after total joint replacement: cumulative results from worldwide joint register datasets. J Bone Joint Surg Br. 2011;93:293-297.

11. Yan Y, Neville A, Dowson D. Tribo-corrosion properties of cobalt-based medical implant alloys in simulated biological environments. Wear. 2007;263:1105-1111.

12. Yan $Y$, Neville A, Dowson D. Understanding the role of corrosion in the degradation of metal-on-metal implants. Proc Inst Mech Eng $\mathrm{H}$. 2006;220:173-181.

13. Brown SA, Hughes PJ, Merritt K. In vitro studies of fretting corrosion of orthopaedic materials. J Orthop Res. 1988;6:572-579.

14. Jacobs JJ, Gilbert JL, Urban RM. Corrosion of metal orthopaedic implants. J Bone Joint Surg Am. 1998;80:268-282.

15. Maloney WJ, Smith RL, Schmalzried TP, et al. Isolation and characterization of wear particles generated in patients who have had failure of a hip arthroplasty without cement. J Bone Joint Surg Am. 1995;77:13011310.

16. Urban RM, Jacobs JJ, Sumner DR, et al. The bone-implant interface of femoral stems with non-circumferential porous coating. J Bone Joint Surg Am. 1996;78:1068-1081.

17. Urban RM, Jacobs JJ, Tomlinson MJ, et al. Dissemination of wear particles to the liver, spleen, and abdominal lymph nodes of patients with hip or knee replacement. J Bone Joint Surg Am. 2000;82:457-476.

18. Howie DW. Tissue response in relation to type of wear particles around failed hip arthroplasties. J Arthroplasty. 1990;5:337-348.

19. Cooper HJ, Urban RM, Wixson RL, et al. Adverse local tissue reaction arising from corrosion at the femoral neck-body junction in a dual-taper stem with a cobalt-chromium modular neck. J Bone Joint Surg Am. 2013;95:865-872.

20. Bradberry SM, Wilkinson JM, Ferner RE. Systemic toxicity related to meta hip prostheses. Clin Toxicol (Phila). 2014;52:837-847.

21. Kwon YM, Fehring TK, Lombardi AV, et al. Risk stratification algorithm for management of patients with dual modular taper total hip arthroplasty: consensus statement of the American Association of Hip and Knee Surgeons, the American Academy of Orthopaedic Surgeons and the Hip Society. J Arthroplasty. 2014;29:2060-2064.

22. Pivec R, Meneghini RM, Hozack WJ, et al. Modular taper junction corrosion and failure: how to approach a recalled total hip arthroplasty implant. J Arthroplasty. 2014;29:1-6.

23. Nawabi DH, Do HT, Ruel A, et al. Comprehensive analysis of a recalled modular total hip system and recommendations for management. J Bone Joint Surg Am. 2016;98:40-47.
24. Ng SK, Ebneter A, Gilhotra JS. Hip-implant related chorio-retinal cobalt toxicity. Indian J Ophthalmol. 2013;61:35-37.

25. Devlin JJ, Pomerleau AC, Brent J, et al. Clinical features, testing, and management of patients with suspected prosthetic hip-associated cobalt toxicity: a systematic review of cases. J Med Toxicol. 2013;9:405-415.

26. Ratner BD. A perspective on titanium biocompatibility. In: Titanium in Medicine: Material Science, Surface Science, Engineering, Biological Responses and Medical Applications. Brunette DM, Tengvall P, Textor M, Thomsen P (eds.) Springer Berlin Heidelberg: Berlin, Heidelberg; pp. 1-12; 2001.

27. McAlister IP, Abdel MP. Elevated serum titanium level as a marker for failure in a titanium modular fluted tapered stem. Orthopedics. 2016;39:e768- e770

28. Valles G, Gonzalez-Melendi P, Gonzalez-Carrasco JL, et al. Differential inflammatory macrophage response to rutile and titanium particles. Biomaterials. 2006;27:5199-5211.

29. Cai K, Hou Y, Hu Y, et al. Correlation of the cytotoxicity of $\mathrm{TiO}_{2}$ nanoparticles with different particle sizes on a sub-200-nm scale. Small. 2011;7:3026-3031.

30. Mathew MT, Pai PS, Pourzal R, et al. Significance of tribocorrosion in biomedical applications: overview and current status. Adv Tribol. 2009;2009:Article ID 250986

31. Poitout DG. Biomechanics and Biomaterials in Orthopedics, 2nd ed. New York: Springer, 2016.

32. Grosse $S$, Haugland HK, Lilleng $P$, et al. Wear particles and ions from cemented and uncemented titanium-based hip prostheses-a histological and chemical analysis of retrieval material. J Biomed Mater Res B Appl Biomater. 2015;103:709-717.

33. Fujishima $A$, Zhang $X T$, Tryk DA. $\mathrm{TiO}_{2}$ photocatalysis and related surface phenomena. Surf Sci Rep. 2008;63:515-582.

34. Shi H, Magaye R, Castranova V, et al. Titanium dioxide nanoparticles: a review of current toxicological data. Part Fibre Toxicol. 2013;10:15.

35. Sayes CM, Wahi R, Kurian PA, et al. Correlating nanoscale titania structure with toxicity: a cytotoxicity and inflammatory response study with human dermal fibroblasts and human lung epithelial cells. Toxicol Sci. 2006;92:174-185.

36. Hussain S, Boland S, Baeza-Squiban A, et al. Oxidative stress and proinflammatory effects of carbon black and titanium dioxide nanoparticles: role of particle surface area and internalized amount. Toxicology. 2009;260:142-149.

37. Gurr JR, Wang AS, Chen $\mathrm{CH}$, et al. Ultrafine titanium dioxide particles in the absence of photoactivation can induce oxidative damage to human bronchial epithelial cells. Toxicology. 2005;213:66-73.

38. Warheit DB, Webb TR, Sayes CM, et al. Pulmonary instillation studies with nanoscale $\mathrm{TiO}_{2}$ rods and dots in rats: toxicity is not dependent upon particle size and surface area. Toxicol Sci. 2006;91:227-236.

39. Cheng LC, Jiang X, Wang J, et al. Nano-bio effects: interaction of nanomaterials with cells. Nanoscale. 2013;5:3547-3569.

40. Riu J, Maroto A, Rius FX. Nanosensors in environmental analysis. Talanta. 2006;69:288-301.

41. Okafor CC, Haleem-Smith $\mathrm{H}$, Laqueriere $\mathrm{P}$, et al. Particulate endocytosis mediates biological responses of human mesenchymal stem cells to titanium wear debris. J Orthop Res. 2006;24:461-473.

42. Hou Y, Cai K, Li J, et al. Effects of titanium nanoparticles on adhesion, migration, proliferation, and differentiation of mesenchymal stem cells. Int J Nanomedicine. 2013;8:3619-3630.

43. Jacobs JJ, Hallab NJ, Urban RM, et al. Wear particles. J Bone Joint Surg Am. 2006;88 Suppl 2:99-102.

44. Archibeck MJ, Jacobs JJ, Roebuck KA, et al. The basic science of periprosthetic osteolysis. Instr Course Lect. 2001;50:185-195.

45. Haleem-Smith H, Argintar E, Bush C, et al. Biological responses of human mesenchymal stem cells to titanium wear debris particles. J Orthop Res. 2012;30:853-863.

46. Meng B, Yang $X$, Chen $Y$, et al. Effect of titanium particles on osteoclast activity in vitro. Mol Med Rep. 2010;3:1065-1069.

47. Morimoto $\mathrm{Y}$, Kobayashi N, Shinohara N, et al. Hazard assessments of manufactured nanomaterials. J Occup Health. 2010:52:325-334.

48. Karlsson HL, Gustafsson J, Cronholm P, et al. Size-dependent toxicity of metal oxide particles - a comparison between nano- and micrometer size. Toxicol Lett. 2009;188:112-118.

49. Geiser M, Rothen-Rutishauser B, Kapp N, et al. Ultrafine particles cross cellular membranes by nonphagocytic mechanisms in lungs and in cultured cells. Environ Health Perspect. 2005;113:1555-1560. 
50. Pioletti DP, Takei $\mathrm{H}$, Kwon SY, et al. The cytotoxic effect of titanium particles phagocytosed by osteoblasts. J Biomed Mater Res. 1999;46:399-407.

51. Yao J, Cs-Szabo G, Jacobs JJ, et al. Suppression of osteoblast function by titanium particles. J Bone Joint Surg Am. 1997;79:107-112.

52. Ribeiro AR, Gemini-Piperni S, Travassos R, et al. Trojan-like internalization of anatase titanium dioxide nanoparticles by human osteoblast cells. Sci Rep. 2016;6:23615.

53. Nevo Y, Nelson N. The NRAMP family of metal-ion transporters. Biochim Biophys Acta. 2006;1763:609-620.

54. Smith AT, Smith KP, Rosenzweig AC. Diversity of the metal-transporting P1B-type ATPases. J Biol Inorg Chem. 2014;19:947-960.

55. Tay CY, Setyawati MI, Xie J, et al. Back to basics: exploiting the innate physico-chemical characteristics of nanomaterials for biomedical applications. Adv Funct Mater. 2014;24:5936-5955.

56. Peters K, Unger RE, Kirkpatrick CJ, et al. Effects of nano-scaled particles on endothelial cell function in vitro: studies on viability, proliferation and inflammation. J Mater Sci Mater Med. 2004;15:321-325.

57. Thurn KT, Arora H, Paunesku T, et al. Endocytosis of titanium dioxide nanoparticles in prostate cancer PC-3 M cells. Nanomedicine. 2011;7: $123-130$

58. Zhang $Y, Y u$ W, Jiang $X$, et al. Analysis of the cytotoxicity of differentially sized titanium dioxide nanoparticles in murine MC3T3-E1 preosteoblasts. J Mater Sci Mater Med. 2011;22:1933-1945.

59. Zhang J, Song W, Guo J, et al. Cytotoxicity of different sized $\mathrm{TiO}_{2}$ nanoparticles in mouse macrophages. Toxicol Ind Health. 2013;29:523-533.

60. Wang ML, Tuli R, Manner PA, et al. Direct and indirect induction of apoptosis in human mesenchymal stem cells in response to titanium particles. J Orthop Res. 2003;21:697-707.

61. Wang ML, Nesti LJ, Tuli R, et al. Titanium particles suppress expression of osteoblastic phenotype in human mesenchymal stem cells. J Orthop Res. 2002;20:1175-1184.

62. Bernier MC, El Kirat K, Besse M, et al. Preosteoblasts and fibroblasts respond differently to anatase titanium dioxide nanoparticles: a cytotoxicity and inflammation study. Colloids Surf B Biointerfaces. 2012;90:68-74.

63. Rahman $Q$, Lohani $M$, Dopp $E$, et al. Evidence that ultrafine titanium dioxide induces micronuclei and apoptosis in Syrian hamster embryo fibroblasts. Environ Health Persp. 2002;110:797-800.

64. Vamanu Cl, Cimpan MR, Hol PJ, et al. Induction of cell death by $\mathrm{TiO}_{2}$ nanoparticles: studies on a human monoblastoid cell line. Toxicol In Vitro. 2008;22:1689-1696.

65. Wu J, Sun J, Xue Y. Involvement of JNK and P53 activation in G2/M cell cycle arrest and apoptosis induced by titanium dioxide nanoparticles in neuron cells. Toxicol Lett. 2010;199:269-276.

66. Landgraeber S, von Knoch M, Loer F, et al. Extrinsic and intrinsic pathways of apoptosis in aseptic loosening after total hip replacement. Biomaterials. 2008;29:3444-3450.

67. Mahmoudi M, Azadmanesh K, Shokrgozar MA, et al. Effect of nanoparticles on the cell life cycle. Chem Rev. 2011;111:3407-3432.

68. Niska K, Pyszka K, Tukaj C, et al. Titanium dioxide nanoparticles enhance production of superoxide anion and alter the antioxidant system in human osteoblast cells. Int J Nanomedicine. 2015;10:1095-1107.

69. Dobrzynska MM, Gajowik A, Radzikowska J, et al. Genotoxicity of silver and titanium dioxide nanoparticles in bone marrow cells of rats in vivo. Toxicology. 2014;315:86-91.

70. Kadoya Y, al-Saffar N, Kobayashi A, et al. The expression of osteoclast markers on foreign body giant cells. Bone Miner. 1994;27:85-96.

71. Falck GC, Lindberg HK, Suhonen S, et al. Genotoxic effects of nanosized and fine $\mathrm{TiO}_{2}$. Hum Exp Toxicol. 2009;28:339-352.

72. Huang S, Chueh PJ, Lin YW, et al. Disturbed mitotic progression and genome segregation are involved in cell transformation mediated by nano- $\mathrm{TiO}_{2}$ long-term exposure. Toxicol Appl Pharmacol. 2009;241: 182-194.

73. Magdolenova Z, Bilanicova D, Pojana G, et al. Impact of agglomeration and different dispersions of titanium dioxide nanoparticles on the human related in vitro cytotoxicity and genotoxicity. J Environ Monit. 2012;14:455-464.

74. Tautzenberger A, Kovtun A, Ignatius A. Nanoparticles and their potential for application in bone. Int J Nanomedicine. 2012;7:4545-4557.

75. He X, Hartlieb E, Rothmund L, et al. Intracellular uptake and toxicity of three different Titanium particles. Dent Mater. 2015;31:734-744.

76. AshaRani PV, Low Kah Mun G, Hande MP, et al. Cytotoxicity and genotoxicity of silver nanoparticles in human cells. ACS Nano. 2009;3:279-290.
77. Setyawati M, Tay C, Chia S, et al. Titanium dioxide nanomaterials cause endothelial cell leakiness by disrupting the homophilic interaction of VE-cadherin. Nat Commun. 2013;4:1673.

78. Setyawati MI, Tay CY, Docter D, et al. Understanding and exploiting nanoparticles' intimacy with the blood vessel and blood. Chem Soc Rev. 2015;44:8174-8199.

79. Braydich-Stolle LK, Schaeublin NM, Murdock RC, et al. Crystal structure mediates mode of cell death in $\mathrm{TiO}_{2}$ nanotoxicity. J Nanopart Res. 2009;11:1361-1374.

80. Wei MC, Zong WX, Cheng EH, et al. Proapoptotic BAX and BAK: a requisite gateway to mitochondrial dysfunction and death. Science. 2001;292: 727-730.

81. Lindsten $T$, Ross AJ, King A, et al. The combined functions of proapoptotic $\mathrm{Bcl}-2$ family members Bak and Bax are essential for normal development of multiple tissues. Mol Cell. 2000;6:1389-1399.

82. Zhu Y, Eaton JW, Li C. Titanium dioxide $\left(\mathrm{TiO}_{2}\right)$ nanoparticles preferentially induce cell death in transformed cells in a Bak/Bax-independent fashion. PLoS One 2012;7:e50607.

83. Choi MG, Koh HS, Kluess D, et al. Effects of titanium particle size on osteoblast functions in vitro and in vivo. Proc Natl Acad Sci U S A. 2005;102:4578-4583.

84. Zreiqat $\mathrm{H}$, Crotti TN, Howlett $\mathrm{CR}$, et al. Prosthetic particles modify the expression of bone- related proteins by human osteoblastic cells in vitro. Biomaterials. 2003;24:337-346.

85. Lohmann CH, Schwartz Z, Koster G, et al. Phagocytosis of wear debris by osteoblasts affects differentiation and local factor production in a manner dependent on particle composition. Biomaterials. 2000;21:551-561.

86. Chen $M$, Chen PM, Dong QR, et al. p38 Signaling in titanium particleinduced MMP-2 secretion and activation in differentiating MC3T3-E1 cells. J Biomed Mater Res A. 2014;102:2824-2832.

87. Brew K, Dinakarpandian D, Nagase $H$. Tissue inhibitors of metalloproteinases: evolution, structure and function. Biochim Biophys Acta. 2000;1477:267-283.

Cite this article as: Yao JJ, Lewallen EA, Trousdale WH, Xu W, Thaler $\mathrm{R}$ Salib CG, Reina N, Abdel MP, Lewallen DG, van Wijnen AJ (2017) Local cellular responses to titanium dioxide from orthopedic implants, BioResearch Open Access 6:1, 94-103, DOI: 10.1089/biores.2017.0017.

$\begin{aligned} & \text { Abbreviations Used } \\ \mathrm{MSCs}^{=}=\text {mesenchymal stem/stromal cells } & \mathrm{TiO}_{2}=\text { titanium dioxide } \\ \mathrm{TJA}= & \text { total joint arthroplasty }\end{aligned}$

